\title{
¿UN ENIGMA HISTÓRICO-GEOGRÁFICO RESUELTO? \\ LA INTERCOMUNICACIÓN DE LAS CUENCAS HIDRICAS DEL PAINE Y LAGO ARGENTINO
}

MATEO MARTINIC B.

\begin{abstract}
RESUMEN
Se entrega información acerca del fenómeno de retroceso del glaciar Dickson en la Patagonia austral andina y de la nueva situación geográfica allí generada en consecuencia, que sugiere la posibilidad de una intercomunicación entre las cuencas del lago Dickson y la laguna Frías que desaguan, respectivamente, al océano Pacífico y al océano Atlántico. Se analiza y evalúa el fenómeno a la luz de los antecedentes históricos que recogieron las hipótesis de intercomunicación sobre la base de las primeras observaciones, incluyendo algunas consecuencias políticas.
\end{abstract}

PALABRAS CLAVES: Patagonia andina, cuencas hidrográficas, retroceso glaciar, cambio climático.

$$
\begin{aligned}
& \text { ¿A RESOLVED HISTORIC-GEOGRAPHIC ENIGMA? } \\
& \text { THE INTECOMUNICATION OF PAINE AND ARGENTINO LAKE BASINS }
\end{aligned}
$$

\begin{abstract}
Information about glacier Dickson retreat phenomena, Andean Southernmost Patagonia, is given. Also about the new geographic situation generated, which suggests intercommunication between Dickson Lake and Frías lagoon, which drain to the Pacific and Atlantic oceans, respectively. The phenomenon is analyzed and assessed at the light of the historic background that reported the hypothesis of intercommunication based on first observations, including some political consequences.
\end{abstract}

KEYWORDS: Andean Patagonia, hydrographic basins, glacial retreat, climatic change. 


\section{INTRODUCCIÓN}

Durante los últimos años y en cada oportunidad en que viajamos por vía aérea entre Punta Arenas y Puerto Montt o Santiago y tuvimos la suerte de sentarnos junto a una ventana en la parte delantera de la cabina, y con buena posibilidad de visión, junto con adecuadas condiciones para la observación (cielo despejado y luminosidad), procuramos estar atentos al paisaje bajo el avión, en especial al sobrevolar el área del Parque Nacional "Torres del Paine" y, en particular el sector del lago Dickson. En el caso nos ha interesado observar el proceso de retroceso del glaciar homónimo, fenómeno en ocurrencia desde largo tiempo atrás. Ello formaba, como forma parte de un antiguo hábito de observación geográfica de la Patagonia andina. Así, en tres oportunidades pudimos constatar como el glaciar Dickson retrocedía notoriamente y disminuía por consecuencia su tamaño, tanto como para dar origen, por angostamiento de su lengua meridional, a un canalizo por su margen izquierda (primeras observaciones), que después advertimos servía para evacuar las aguas de un sector septentrional del lago hasta entonces cubierto por el hielo y progresivamente liberado del mismo por retroceso y derretimiento glaciar, inclusive sugiriendo una aparente comunicación (desagüe) entre la cuenca de dicho lago y la vecina septentrional de la laguna Frías (última observación). Esta circunstancia, aparentemente inadvertida para muchos por ausencia de mención en los medios de comunicación, trajo a nuestra memoria las hipótesis de intercomunicación fluviolacustre entre ambas cuencas que se plantearon al tiempo de las primeras exploraciones y reconocimientos en esa sección de la Patagonia austral andina, aspecto cuya revisión nos parece de interés a la luz del fenómeno de deglaciación en actual desarrollo.

\section{ANTECEDENTES HISTÓRICOS SOBRE EL CONOCIMIENTO DE LA GEOGRAFÍA LOCAL}

Históricamente la primera aproximación al sector andino que interesa la hizo el teniente de la Armada de Chile, Juan Tomás Rogers, en el transcurso de su segunda exploración a la Patagonia austral por encargo del Gobierno Chileno. Ella se dio a principios de 1879 cuando Rogers exploraba el sector del "lago del Misterio", según lo denominaban los baqueanos que lo acompañaban, para resolver si se trataba de un depósito separado del lago Santa Cruz o Argentino, o si formaba parte del mismo como lo intuía y luego pudo comprobarlo. El día 4, observando desde un cerro en procura de una visión panorámica del sector, advirtió [...] otra abra que corría al SO. de donde parecía venir el viento. Al S. de esta abra quedaban dos altos picos nevados, siendo tal vez uno de ellos el Stokes ${ }^{1}$, en lo que fue el primer registro para la ciencia de tal circunstancia geográfica. Días después tuvo la certidumbre sobre su intuición y pudo comprobar que toda la zona sur que exploraba constituía una extensión del lago Argentino conformada por los actuales brazos Rico y Sur, este advertido como [...] un seno que se prolonga hacia el S. por 6 a 7 millas i que denominamos Encina ${ }^{2}$.

El 14 de febrero, otra observación le permitió a Rogers tener un nuevo dato, ahora sobre el origen de los témpanos que flotaban en el brazo lacustre: En el fondo de la ensenada Encina se divisaba también otro ventisquero; pero no vimos salir témpanos, lo que nos hizo suponer que el ventisquero no desciende hasta las aguas del lago. Por la parte $S$. del morro i hacia el este, se veía algo como una pampa abundante en pantanos. Los cerros que siguen al este principian desde el fondo de la ensenada Encina i los occidentales un poco más al S.; pero no pudimos apreciar sus términos ${ }^{3}$.

Rogers había descubierto de esa manera la depresión que separa dos formaciones orográficas, la cordillera de los Andes y la sierra de los Baguales.

Posteriormente todavía, el 7 de marzo, cuando exploraba el sector del Paine, observando hacia el oeste el oficial anotó en su diario: Parece que el lago donde desemboca el río Blanco [actual río Paine] se prolonga hacia el occidente por una grande extensión. Zamora [el baqueano que lo guiaba], que es la persona que ha penetrado más por esta comarca, no le ha dado fin; por manera que si se prolongase hasta cerca de los canales occidentales, los Andes se hallarían también interrumpidos en esta parte ${ }^{4}$.

1 Segunda exploración de la parte austral de la Patagonia. En Marinos de a caballo. Exploraciones terrestres de la Armada de Chile en la Patagonia austral y la Tierra del Fuego 1877-1897. Edición, introducción y notas de Mateo Martinic B. (Universidad de Magallanes-Universidad de Playa Ancha. Valparaíso 2002), pág. 140.

Id. pág, 143.

Ibid. pág. 147.

Ibid. pág. 160. 
En esta descripción vemos la primera sugerencia sobre una posible intercomunicación entre cuencas hidrográficas al relacionársela con aquella del 4 de febrero y días siguientes, donde el abra observada parecía interrumpir la continuidad orográfica entre la cordillera de los Andes y la cadena que se levanta casi perpendicularmente a la misma hacia el este, la ya mencionada sierra Baguales.

Los siguientes visitantes que exploraron y reconocieron el área geográfica que interesa fueron todos argentinos, Carlos M. Moyano, Agustín del Castillo y Ramón Lista (1883-1892), y lo hicieron en un contexto de necesidad de un mayor y más acabado conocimiento en vista de la doble interpretación que para entonces sustentaban las cancillerías chilena y argentina sobre el curso de la línea limítrofe acordada en 1881, en la parte de los Andes Patagónicos, respecto de si la misma debía ceñirse a la divisoria continental de aguas (tesis chilena) o a las altas cumbres absolutas de la Cordillera (tesis argentina). Así, las cuencas de los sistemas hídricos del Paine y del lago Argentino pasaron a ser materia de especial interés y conjetura ante la posibilidad de su intercomunicación que, de darse, privilegiaba la interpretación argentina que fundaba la aspiración de dominio territorial sobre el atractivo distrito interior de Ultima Esperanza. La incógnita estaba en saber qué ocurría en la zona interior alto andina donde parecían confluir los espejos lacustres.

El primero de los exploradores nombrados se hallaba el 12 de enero de 1884 a la vista de los actuales lagos del Toro y Sarmiento que de primera estimó que conformaban un solo depósito al unirse entre sí por la parte del oeste [...] y que ambos, a su vez se reunen en el lago Argentino, para formar las nacientes del Santa Cruz por medio de un canal de comunicación que la topografía del terreno deja fácilmente adivinar, corriendo al norte por una depresión que dejan las montañas al O. de la Cordillera de los Baguales 5 .

Posteriores observaciones confirmaron a Moyano tal suposición tanto como para que así lo reiterara en su informe al Gobierno y lo graficara (aunque con trazo discontinuo por la falta de información más precisa) en un plano que se publicó

5 Carlos M. Moyano, Viajes de exploración a la Patagonia (1877-1890) (Buenos Aires 1931), pág. 160. con la denominación de Patagonia. Croquis de la parte comprendida entre los paralelos 50 á 53 con el itinerario de [la] expedición efectuada en Noviembre á Febrero de 1883-1884 por el Capitán de la Armada Argentina Carlos M. Moyano y el Subteniente Teófilo de Loqui.

La exploración de Moyano fue seguida poco más de un año después por la realizada por otro oficial naval, el teniente Agustín del Castillo, quien arribó al área denominada por el macizo del Paine en febrero de 1887 y a la vista de las mismas circunstancias naturales observadas por aquel explorador (depósitos lacustres y depresiones entre montañas) discurrió igual que Moyano y, por tanto, procuró cerciorarse acerca de la posibilidad de la intercomunicación entre los lagos Argentino y los del sector en que se encontraba. Para ello buscó un punto de observación apropiado [...] con el objeto de descubrir el giro de las aguas que el gran lago Argentino despide al sur, a fin de constatar su llegada hasta las proximidades del Payne, con lo que me proponía adquirir datos para fundar la suposición de que aquel lago se comunica con el de este último nombré .

Así llegó hasta las orillas del actual lago del Toro, del que dejaría la siguiente y sugerente descripción:

Este vasto e inmenso lago está rodeado por el norte y sur de cordilleras, su ancho es variable, y su largo es desconocido; se ve seguir hacia el oeste hasta donde la vista no lo alcanza ni con el auxilio de buenos anteojos. Allá, muy a la distancia, parece bifurcarse en dos grandes ramas, la del sur gana un abra muy grande de cordilleras regulares en forma, y totalmente cubiertas de nieve, para dirigirse hacia el S.O. La rama del norte contornea el cerro Payne, a cuyo largo debe unir sus aguas detrás de ese cerro.

Tengo motivos para creer que aguas que he visto al norte del Payne y al sur del lago Argentino, sean las de la rama del norte.

Por el sur, y muy inmediato al final este del lago, vimos que las aguas entraban dentro de la Cordillera.

Esto me llamó la atención y creyendo que el lago continuaba por esa parte, resolví dar un

6 Exploración de Santa Cruz y Costas del Pacífico (Ediciones Marymar. Buenos Aires 1979), págs. 57 y 58. 
giro alrededor del cerro del sur a fin de ver si era posible descubrir lo que detrás de él se ocultaba7.

En efecto, así lo hizo siguiendo el río que llamó Don Nicolás y que no era otro que el actual Serrano, en búsqueda de su desagüe, de modo que:

Al caer la tarde subíamos una elevación desde la cual pudimos ver que en dirección al oeste había unas aguas azules estrechadas por las cordilleras y separadas del lago por el cerro que teníamos a nuestro costado. No me cupo duda que esas aguas eran las del gran lago que desde el norte se ven ganar al interior de las cordilleras.

Apresuré mi marcha, y al oscurecer me encontraba en sus orillas comprobando que aquellas aguas no pertenecían al lago mismo sino que eran de un canal que se dirigía por el este de las cordilleras hacia el sur.

A la mañana siguiente monté a caballo y me dirigí al norte descubriendo a poco, que en efecto el canal tomaba su origen en el lago, estando su toma comprendida por el macizo de cordilleras y un gran cerro cortado a pique y estrechada por una tierra elevada que parece ser isla.

Al gran cerro del Este de la boca y que oculta el canal cuando se mira del norte, lo denominé Cerro Moyano, en recuerdo del distinguido explorador de este nombre a quien debe el país importantes servicios.

El descubrimiento de este canal cuyo remate ignoraba, vino a intrigar mi situación obligándome a concebir una hipótesis cuya posible realidad halagaba mi vanidad y mi amor propio.

En efecto: en mis investigaciones anteriores había adquirido más que certidumbre, de que las aguas del gran lago del sur no debían ser otra cosa que las del lago Argentino mismo, o por lo menos que si eran independientes debían estar comunicadas por grandes torrentes, canales $o$ cascadas, suposición que fundaba y fundo en la circunstancia de que, en el espacio que media entre esos dos lagos, se apercibe un vasto descenso de las cordilleras en cuyo plan, en varios puntos se ven aguas caudalosas del mismo color y aspecto que las de ambos lagos. Por otra parte un inmenso ventisquero situado en medio de este espacio de separación y que es por el este causa de un sistema completo de ríos, torrentes y chorrillos me hacía

\footnotetext{
Id. págs. 59 y 60.
}

suponer que alimentara las aguas intermedias entre los dos lagos.

Siendo más que probable la comunicación de estos dos lagos, comunicación que fue supuesta antes que yo por el comandante Moyano y de cuyo hecho no tenía noticia en aquel entonces, porque su parte no me era conocido, era natural que aquel canal que se dirigía al sur podía tener, en el supuesto caso de que se ramificara con los canales del Pacífico, una importancia extrema, porque vendría a establecer una comunicación entre los dos mares.

Obedeciendo a la natural curiosidad, dispuse seguir la playa hasta encontrar su fin no obstante de que él se internaba entre las cordilleras y los montes, en una zona desconocida, acaso sembrada de obstáculos.

Subiendo algunos cerros elevados vi que el canal cuyo ancho varía entre 150 y 200 metros aproximadamente seguía al sur, hasta perderse de vista, bañando siempre las cordilleras del oeste, y rodeado de espesos bosques por el este.

Esta circunstancia me demostraba que aquel canal era interior y puramente argentino porque por el este sólo tenía colinas bajas de insignificante altura ${ }^{8}$.

Con tan interesante observación Agustín Del Castillo fue el primero en comprobar el desagüe del lago del Toro a través del río que dos años después encontraría y remontaría desde el sur el capitán Ramón Serrano Montaner, de la Armada de Chile, con lo que cabe a ambos el mérito de compartir el descubrimiento de este importante curso.

Concluida su exploración en la zona preandina, el teniente Del Castillo se retiró convencido de ser los lagos Argentino y del Toro (entendido este como una parte mayor del Sarmiento), certidumbre que ratificó al conocer posteriormente al capitán Moyano y tratar con él el punto, con lo que al fin pudo asentar en su informe al Instituto Geográfico Argentino la siguiente conclusión:

Creo que el gran lago situado al sur del cerro del Payne y que se extiende al este hasta tocar la tierra baja, no es otra cosa en el supuesto que estén al mismo nivel que el lago mismo Argentino. Fundo esta suposición en el hecho de que existen aguas iguales en aspecto $e$ intermedias entre estos dos lagos, cuya distancia de separación es muy pequeña. Una razón que me sirve para fundar

8 Ibid. págs. 63 y 64. 
esto mismo, es el hecho conocido de que una gran parte del lago Argentino se interna hacia el sur, entre las cordilleras, perdiéndose a poca distancia del cerro Payne y de su ventisquero del norte. Y finalmente, que el lago del Sur contorneando el cerro Payne, se ve despedir un brazo hacia el norte, que se pierde detrás de ese cerro.

Siendo el espacio de separación de esas aguas muy pequeño, y viéndose que en ese lugar existe un vacío de cordilleras que facilita y casi puede decirse acusa la unión, lógico me parece suponerla. A más, ese espacio oculto tiene por el este un vasto ventisquero que es quien lo oculta, ventisquero que por el este da origen a varios ríos caudalosos, y que no es aventurado suponer que por el oeste dé lugar a cosa igual o la formación de un vasto canal o lago, que, a existir, sería el brazo de unión de los dos vastos receptáculos de que tratamos.

Si estas hipótesis se realizan, la comunicación, unión o continuación de los dos lagos debe realizarse detrás del cerro del Payne y de su sistema adyacente .

El último de los exploradores argentinos del sector cordillerano de que se trata fue Ramón Lista, quien lo hizo en dos ocasiones, durante 1890 y 1892. Conocedor de los recorridos y observaciones hechos por sus predecesores concordó con ellos -aunque sin repetir sus penetraciones-, y pudo escribir más tarde Los lagos "Sarmiento" y de "Del Castillo" que hemos mencionado [actuales del Toro y Sarmiento respectivamente] forman una cuenca importante, pero muy poco conocida en sus prolongaciones occidentales trasandinas y por su ángulo septentrional, en donde se cruzan el paralelo $52^{\circ}$ con el meridiano $73^{\circ}$ de Greenwich, recibe un río o canal paralelo á los Andes, que parece salir de la laguna Rica [actual Brazo Rico], no lejos del lago Argentino, con el que aquella se comunica por medio de otro emisario mucho más ancho y aproximadamente trazado en las cartas geográficas.

Como los anteriores, el algo Argentino tiene sus derrames occidentales, que cortan la Cordillera, y por rumbos ignorados van a confundirse con las aguas marinas ${ }^{10}$.

$9 \quad$ Ibid. págs. 81 y 82.

10 Viaje a los Andes Australes, en Anales de la Sociedad Científica Argentina, tomo XLI Primer Semestre de 1896 (Buenos Aires 1896) pág. 10.
Sería esta la última afirmación, compartida por otros exploradores y estudiosos, sin embargo, la que generaría más interés y ante la posibilidad de un doble desagüe del lago Argentino hacia el Atlántico y el Pacífico, circunstancia que de ser efectiva hacía mucho más compleja la situación geopolítica que preocupaba a las cancillerías chilena y argentina ${ }^{11}$.

Sobre esta base, se sucedieron otras expediciones en procura de la dilucidación del enigma, entre las que cabe mencionar la encomendada por el Gobierno Chileno a los antiguos oficiales de la Armada, Recaredo Amengual y Alberto Fuentes, realizada en marzo de 1897 . Sus observaciones y averiguaciones en el sector preandino y andino de que se trata les permitieron concluir [...] que no existe comunicación fluvial alguna entre el lago de Santa Cruz [Argentino] i el lago [brazo] Rico, que es la continuación del anterior hacia el sur por una distancia de cómo 30 millas i los canales occidentales de la Patagonia ${ }^{12}$. Por otra parte los exploradores confirmaron lo que ya se suponía entonces con mayor fundamento, esto es, que el lago Argentino sólo desaguaba como desagua al Atlántico. Y de esa manera concluyó el asunto.

El siguiente explorador del área fue el géologo Otto Nordenskjold, quien dirigía la Expedición Sueca a las Tierras Magallánicas (1895-97). Arribó allí a fines de 1896 y penetró hasta la base misma de los Andes y descubrió varios lagos hasta entonces desconocidos, a uno de los cuales, el más septentrional, dio el nombre de Dickson -hasta cuya cabecera alcanzó- en recuerdo del barón Oscar von Dickson, patrocinador de la expedición. Nordenskjold fue así el primer explorador que avistó el glaciar homónimo, del que tuvo una buena visión acerca de su extensión hacia el norte y noroeste. Curiosamente y aunque la depresión intermontana en que se ubica el lago no debió pasarle desapercibida, en el plano que acompañó el informe correspondiente, Sketch Map of South-Western Patagonia, lo muestra semi circundado por montañas hacia el oeste y el norte.

La noción de que se da cuenta fue ratificada poco después (1899) por el explorador Rodolfo Hauthal, integrante de la Comisión Argentina de Límites, quien recorrió los sectores del lago Dickson

11 Mucho más luego que el explorador Clemente Onelli afirmara haber cruzado desde el lago Argentino al canal Smyth a través de los Andes, lo que probaría ser un embuste.

12 Marinos de a caballo, citado, pág. 247. 
y de la alta cordillera adyacente y disipó cualquier duda que pudiera todavía permanecer tanto acerca de una intercomunicación de cuencas al norte y al sur de la sierra Baguales, así como entre las vertientes oriental y occidental de los Andes entre las latitudes $50^{\circ}$ y $51^{\circ} \mathrm{S}$.

El mejor conocimiento del sector sudoccidental del depósito nombrado, logrado años más tarde, contribuyó a aventar, al parecer definitivamente, la antigua suposición de Moyano y Del Castillo, de una comunicación lacustre o fluvial a través de la depresión que separa a la cordillera de los Andes de la sierra Baguales. Para una mejor comprensión, cabe rescatar la descripción que dejó el geólogo sueco Percy Quensel, luego de una excursión de reconocimiento practicada el 13 de enero de 1908: Pudimos alcanzar el límite sur de este brazo [Rico]. Fui a pie hasta el Lago Frío [laguna Frías] y escalé una montaña. Debajo, hacia el sur, yacía el Lago Dickson, situado entre unos bosques verdes; al norte estaban el Monte Stokes y los glaciares del campo de hielo y el más largo se dividía en dos ramas, una extendiéndose hacia el Lago Dickson y la otra hacia el Lago Frío. Así, me encontraba parado en la divisoria de aguas entre el Lago Argentino y la región del Paine, entre el Atlántico y el Pacífico, mientras el agua de mismo glaciar buscaba caminos diversos ${ }^{13}$.

Una descripción tan precisa reflejaba, por lo demás, el convencimiento que habían compartido años antes los peritos e ingenieros de las comisiones de límites chilena y argentina que habían estudiado el asunto -y por ende los técnicos y geógrafos que habían informado a Su Majestad Británica Eduardo VII para los efectos de la decisión en el arbitraje pactado para resolver la disputa a la que se ha hecho mención precedente- en cuanto que a través de dicha abra o depresión transcurría la divisoria continental de aguas, circunstancia que determinó en esta parte la correspondiente asignación de soberanía en favor de Chile.

El explorador Alberto De Agostini estuvo en el sector andino de que se trata por vez primera en 1916 y retornó en 1929, con lo que consiguió formarse una impresión cabal sobre sus características fisio y glaciográficas.

13 En Carl Skottsberg, La Patagonia salvaje (Zagier \& Urruty Publications, Buenos Aires 2004), pág. 238.
En la cabecera septentrional del Lago Dickson, relataría más tarde, desborda del interior de la Cordillera nevada un extenso glaciar, cuya lengua llega hasta las orillas del lago.

La frente del glaciar aparece en notable retroceso, el que se produjo probablemente desde hace unas pocas decenas de años, como lo demuestra la faja completamente desnuda que cubre actualmente la ladera de la montaña.

Su cuenca de alimentación es muy extensa y cubre toda la vertiente SE del Cerro Gorra, de 1.800 metros, y se origina en un amplio altiplano cubierto de hielo del cual emergen algunas cumbres bellísimas, totalmente blancas, debido a la nieve que las reviste. Por su costado NW el Ventisquero Dickson se comunica, por una profunda depresión glacial, con otra corriente de hielo que desciende de la Cordillera hacia la cuenca del Brazo Rico, del Lago Argentino. El relleno de este boquete glacial de transfluencia, como pude observar en una excursión que efectué en el verano de 1916, subiendo desde el Lago Argentino, está sujeto a intensa ablación y preséntase cubierto de un gran manto de morenas y sembrado de pequeños estanques de deshielo donde se origina el Río Frías que desemboca en el lago del mismo nombre, a pocos kilómetros del Brazo Rico, (Lago Argentino) ${ }^{14}$.

No sería sino hasta pasada la mitad del siglo $\mathrm{XX}$ que se registraría un nuevo reconocimiento de la geografía del área. Ocurrió en 1959 cuando una expedición andinística polaca dirigida por José Peterek, del Centro Andino de Buenos Aires, recorrió el sector de las cuencas de alimentación de los glaciares Dickson, Cubo y Frías aunque sin añadir novedad alguna que alterara la ya antigua noción mencionada.

La cartografía chilena y argentina a partir de 1902 concordaría en la representación de la geografía de esa porción de los Andes Patagónicos por la que transcurre la frontera internacional, con un trazado que partiendo desde el cerro Daudet hacia el Cubo cortaba el doble flujo glacial, según se lo entendía entonces, sin otra modificación que la mutuamente convenida en 1998 entre los gobiernos de Chile y Argentina para precisar el curso de la línea demarcatoria de jurisdicciones y que posteriormente fue ratificado por los correspondientes

14 Andes Patagónicos (Buenos Aires, 1945), pág. 111. 


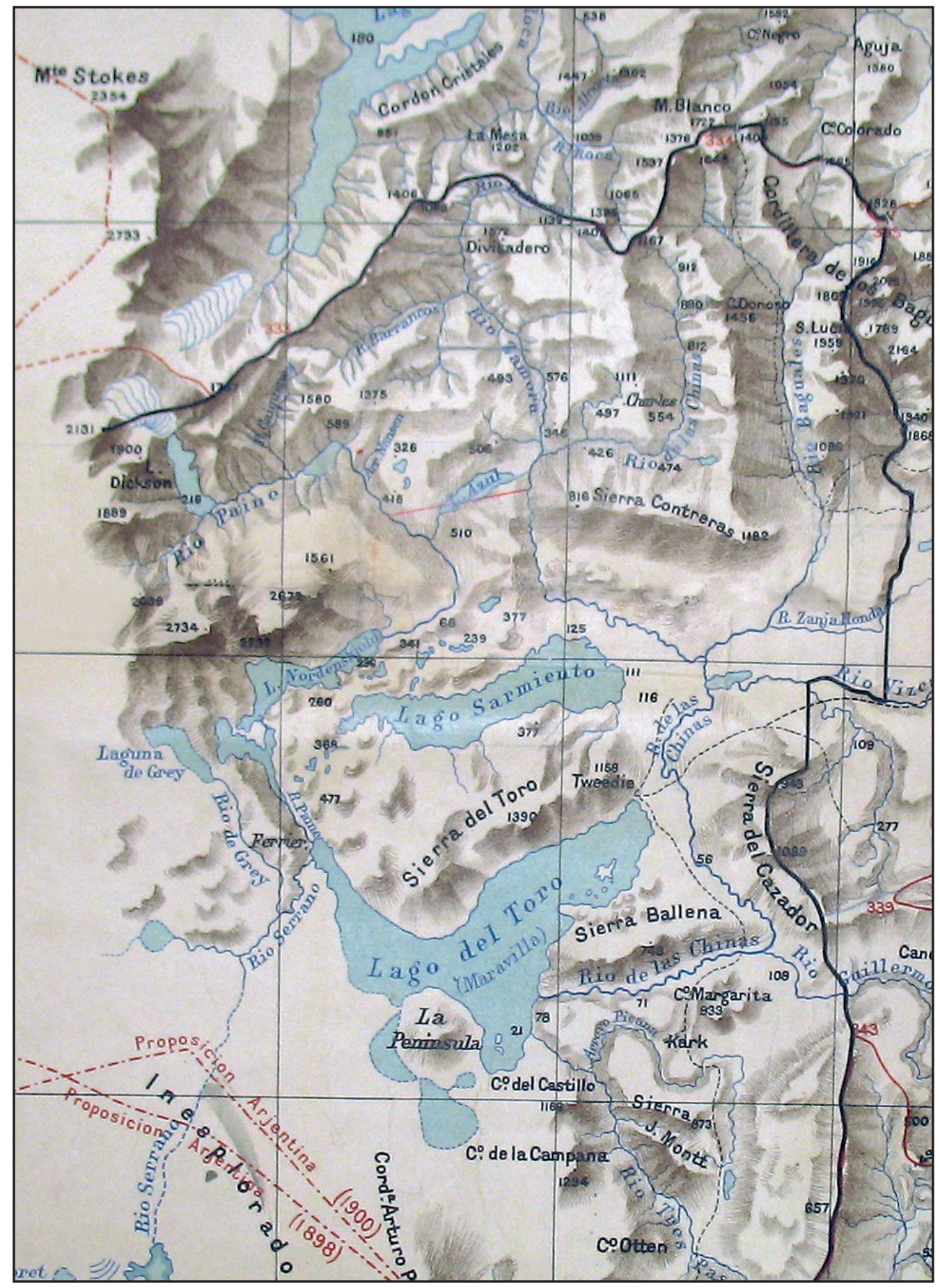

Fig. 1. Sector de la divisoria orográfica entre las cuencas del Paine y lago Argentino que muestra la traza del laudo arbitral de 1902 (Plano IX Entre 49 y 52 Lat. S.) Demarcación de Límites entre Chile y la Republica Argentina. Comisión Chilena de Límites, 1906. 
congresos nacionales durante 1999, con lo que el acuerdo asumió el carácter de un tratado solemne.

En efecto, en el sector como en otros del tramo de frontera comprendido entre los montes Fitz Roy y Daudet, las propuestas correspondientes eran divergentes, orientándose inicialmente la chilena desde el último monte hacia el oeste y quebrando luego de un trecho hacia el NNE, en tanto que la argentina arrancaba del Daudet y seguía al SO con algunas inflexiones menores que correspondían al parecer a las variaciones de las corrientes de alimentación glaciar, hasta el monte Stokes, y continuaba desde allí con un giro pronunciado con dirección general norte. En lo que interesa, el acuerdo se estableció sobre la base de la traza del laudo de 1902 entre los montes Daudet y Stokes, que era prácticamente idéntica a la propuesta argentina. Desde este último punto la línea del acuerdo se cierra sobre la traza anterior tomando la dirección NNE hasta encontrarse con la propuesta chilena. Se generó así una suerte de cuchilla o cuña muy angosta de unos ocho kilómetros de largo aproximadamente a modo de penetración al suroeste, en un trazado que se advierte respondió al propósito de anclarlo al punto monte Stokes, según lo definiera el laudo arbitral de $1902^{15}$.

Como consecuencia del acuerdo de 1998 la lengua del glaciar Dickson quedó bisectada aproximadamente hacia su sector central dejando la curiosa figura de una corriente glaciar bajo jurisdicción chilena en sus partes superior y terminal y argentina en una estrecha faja intermedia.

Sin embargo de ello, este codo orográfico de la línea de frontera internacional reservaba una sorpresa.

\section{DINAMISMO GLACIAL}

Aunque los movimientos de retroceso y avance en los glaciares patagónicos (Campo de Hielo Patagónico Norte y Campo de Hielo Patagónico Sur) fueron advertidos desde el principio del siglo XX, no fue sino hacia la mitad del mismo que comenzó un

15 Para una mejor comprensión de lo expuesto sugerimos consultar el mapa Campo de Hielo Patagónico Sur, incluido en el artículo "Campo de Hielo Patagónico Sur: su historia", por Gino Casassa y Andrés Rivera (Anales del Instituto de la Patagonia, serie Ciencias Humanas, vol. 29:29-78. Punta Arenas, 2001) estudio sistemático de esos fenómenos. Los mismos se iniciaron con la observación del fenómeno en el glaciar Moreno -lejos el más espectacular- y en el glaciar Pío XI, ambos del Campo de Hielo Patagónico Sur, aquél en su vertiente oriental y éste en la occidental. Respecto de otros glaciares con acceso ocasional o aperódico -como el Balmaceda-, una forma común de registro fue la comparación entre fotografías antiguas y modernas de sus correspondientes lóbulos frontales.

Esa fue, precisamente, la referencia en el caso del glaciar Dickson, comenzando con una vista realizada en 1901 por el geógrafo Lucien Gallois, toma que se comparó con la realizada en 1943 por el explorador Alberto De Agostini. La medición correspondiente ha permitido determinar un retroceso promedio de 17 metros por año (Lliboutry, 1956), esto es, poco más de 700 metros para el período, cifra que sin embargo de su importancia relativa parecía no llamar especialmente la atención en el ambiente científico, tanto porque era inferior a la registrada en otros glaciares, como por la circunstancia de ser muy contados los observadores que accedían hasta las márgenes del lago Dickson. De ese modo, este depósito se representó en los mapas con una superficie en apariencia invariable, del orden de $90 \mathrm{~km}^{2}$.

Una mayor atención sobre lo que allí acontecía se tuvo a contar de 1982 cuando se produjo una repentina elevación en el nivel de las aguas del río Paine, con consecuencias de inundación de sectores ribereños, circunstancia que motivó la preocupación del personal y autoridades de la Corporación Nacional Forestal a los que cabe la tuición y administración del Parque Nacional "Torres del Paine", del mismo modo que a los funcionarios regionales de la Dirección General de Aguas del Ministerio de Obras Públicas. La investigación reveló como causa el vaciamiento repentino de un lago glacial en la zona de confluencia de los glaciares Dickson y Frías ${ }^{16}$, suceso del que no se conocían precedentes históricos.

Así, de entonces en adelante, las observaciones periódicas con los correspondientes registros fotográficos, que incluyeron sobrevuelos ocasionales, pusieron en evidencia un particular dinamismo gla-

16 Fenómeno conocido en glaciología con la palabra islandesa jökullhlaup y en inglés como glacial lake outburst flood, glof en su abreviación, que ha pasado a ser la forma más utilizada. 
ciar, ya considerado años antes por Lliboutry en su estudio de las primeras fotografías aéreas realizadas en 1945 por la American Air Force por encargo del Gobierno de Chile, y atribuida por este glaciólogo a la baja de nivel del Hielo Patagónico vecino, que ya no puede alimentar al Glaciar Frías, virtiéndose por encima del cordón limítrofe, y se vierte todo hacia el Fiordo Calvo, al oeste ${ }^{17}$.

En efecto, la alimentación de los glaciares Dickson y Frías se hacía originalmente por una sola corriente de hielo formada en la zona del cerro Cubo, que luego se bifurcaba, una hacia el sureste formando el primero de los cursos nombrados y otra hacia el noreste, dando origen al Frías. Ahora bien, debido a la deglaciación de dicha cuenca, como en general en todo el Campo de Hielo Patagónico Sur a partir del quinto final del siglo XX, el receso glaciar se hizo más pronunciado y notorio por la fusión de gran cantidad de hielo cuyas aguas encontraron una vía de escape en la zona de contacto del Dickson con la ribera rocosa de la margen izquierda del lago homónimo, flujo que a su vez aceleró el deshielo y la evacuación, con resultado del vaciamiento de un depósito formado en la zona norte de separación de aquél con el Frías.

En efecto, tal se pudo constatar en la comisión de inspección realizada el 7 de noviembre de 1998 conjuntamente por personal de CONAF y DGA-MOP y la concurrencia del glaciólogo Andrés Rivera, del Centro de Estudios Científicos de Valdivia, y con el apoyo de la Fuerza Aérea de Chile que puso a disposición de la misma un helicóptero para el sobrevuelo del área con lo que pudo conseguirse un acabado reconocimiento tanto terrestre como aéreo.

Primeramente se efectuaron varios sobrevuelos sobre el glaciar observándose un gran retroceso de éste y una gran cantidad de grietas hacia el frente norte (en dirección al glaciar Frías). En la confluencia del glaciar Dickson y Frías se observó una gran cantidad de material morrénico lo que demuestra que el glaciar ha sufrido un importante adelgazamiento. Durante el sobrevuelo de la morrena se pudo observar que desde el glaciar Frías fluye agua en dirección al lago Dickson, es decir el glaciar Frías aporta aguas tanto al océano Atlántico como al Pacífico.

17 Nieves y glaciares de Chile (Editorial Universitaria, Santiago de Chile, 1956), pág. 401.
En el margen del glaciar con el cerro Daudet se observó la existencia de un canal que une la laguna en formación con el lago Dickson existiendo un flujo continuo de agua desde la laguna al lago.

[...] Se efectuó un reconocimiento completo siguiendo el curso del canal que desagua a la laguna en formación; este canal fue la vía de evacuación en el vaciamiento de una represa glacial el año 1982; se observó un flujo continuo del agua con muy bajas velocidades.

Se debe destacar que en la actualidad el lago Dickson está prácticamente al mismo nivel que en el lago en formación o represa glacial (confluencia G. Dickson y Frías) es decir la represa es una continuación del lago Dickson ${ }^{18}$.

De ese modo se ha comprobado entre 1982 y 2010 tanto el retroceso progresivo del glaciar Dickson, como el crecimiento superficial del lago del mismo nombre. El primer fenómeno lo ha sido en sucesivas mediciones registradas en 1984, 1986, 1995, 1998 y 2010 (esta sobre la base del examen de una fotografía satelital), con resultado de un retroceso acumulado de 4,8 kilómetros, lo que añadido al cálculo de Lliboutry mencionado, totaliza 5,5 kilómetros de retroceso entre 1897 y 2010 , con la particularidad notable de haber cobrado el fenómeno un ritmo varias veces mayor entre 1943 y 2010 que el registrado para el período 1897-1943.

No nos corresponde conjeturar acerca de si la causa del fenómeno puede atribuirse al denominado "calentamiento global", aunque pensamos que el desarrollo del mismo más bien debiera situarse en el mayor contexto de la dinámica recesiva del gran fenómeno glaciario que cobró su máxima expresión sudcontinental hace cosa de un millón de años atrás, circunstancia que por sí misma ha dado forma a la historia glaciológica de la Patagonia y la Tierra del Fuego ${ }^{19}$. En la consideración de las causas del

18 Informe de situación formación laguna en glaciar Dickson, sin fecha, Ministerio de Obras Públicas Dirección General de Aguas XII Región Magallanes y Antártica Chilena, suscrito por el señor Sergio Díaz H., a quien debemos la información, que agradecemos.

19 Debe tenerse presente que la mayor parte de los campos glaciares se encuentra en la parte austral del continente, de los que los más importantes son los denominados Hielo Patagónico Norte, Hielo Patagónico Sur y Campo de Hielo de la Cordillera Darwin. De acuerdo con el glaciólogo M. Aniya, entre 1994 y 1986 la reducción de la superficie glaciar puede estimarse en $500 \mathrm{Km}^{2}$; Gino Casassa y otros, han estimado que para el período 1986-2000 la pérdida de área alcanza a 321,4 Km². 


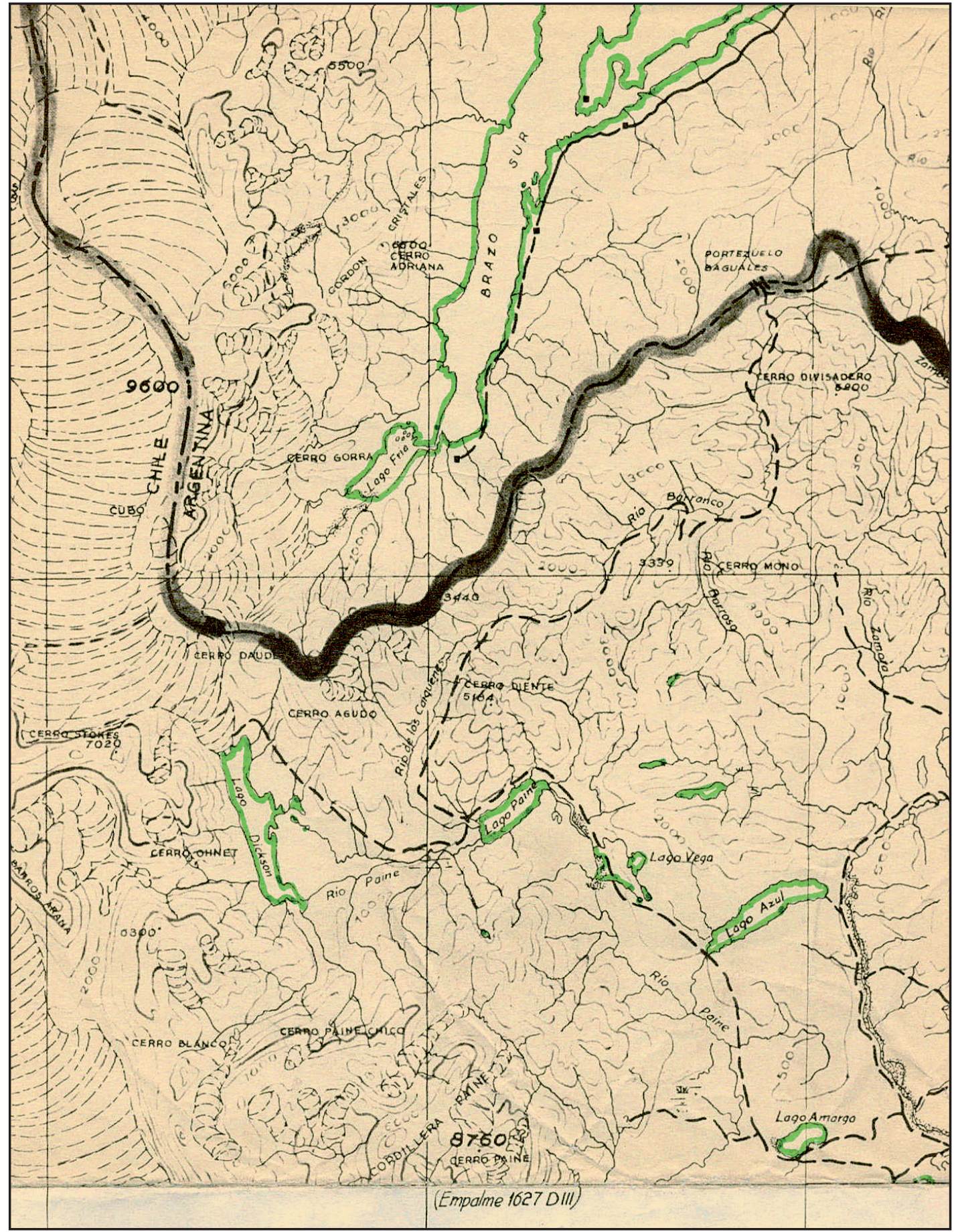

Fig. 2. Sector de la divisoria entre las cuencas del Paine y lago Argentino (Parte del mapa elaborado por US Geological Survey sobre la base de las fotografías trimetrogónicas tomadas desde enero a marzo de 1945 por la United States Air Force USAF). 
fenómeno nos atrevemos a sugerir como conjetura aceptable la circunstancia conocida de "calderas volcánicas" bajo el suelo gélido, que podrían influir en su desarrollo, como se ha planteado por algunos autores y recogido en otro trabajo nuestro ${ }^{20}$.

El crecimiento del lago Dickson, de una longitud histórica aproximada de diez kilómetros hasta el doble virtualmente que hoy muestra la imagen satelital entrega los siguientes aumentos de tamaño: $1945,94,5 \mathrm{~km}^{2} ; 1985,103 \mathrm{~km}^{2} ; 1997,122,3 \mathrm{~km}^{2}$ y 2010, 159,3 $\mathrm{km}^{2}$. Las mediciones se han hecho sobre dos mapas, el Plano Preliminar de AAF (1627 "D”) Lago Argentino (escala 1:250.000) sobre cuya base se construyó el cuarterón Cerro Chaltel o Fitz Roy 4900-7200 del Instituto Geográfico Militar de Chile, en idéntica escala; y el plano Paine incluido en el libro Patagonia de Gino Buscaini y Silvia Metzeltin; y, además, sobre imágenes satelitales actuales. Todo indica que el retroceso del ahora único lóbulo glaciar proseguirá en el futuro, con una ampliación de la superficie lacustre que en su desarrollo hacia el noreste podría llenar (si el nivel del terreno lo permite) el espacio ocupado por una pequeña laguna contigua.

Pero tan interesante doble fenómeno no obstante que seguido por especialistas como Gino Casassa y Andrés Rivera, del Centro de Estudios Científicos de Valdivia, no ha tenido difusión por ausencia de cobertura mediática, como ha ocurrido con otros glaciares tales como el Témpano y el San Rafael, en la vertiente occidental del Hielo Patagónico Sur; el Jorge Montt y el O'Higgins en laboreal, y el Upsala, el Grey o el Tyndall en la oriental, principalmente, tanto más que el mismo ha dado origen a una inesperada consecuencia política, según pasa a exponerse en el siguiente parágrafo.

Queda por ver si el aumento progresivo del lago Dickson según lo hace la fusión de su cuenca de alimentación glacial, está originando una doble vertiente fluvial hacia el sur y hacia el noreste mediante la conexión de la laguna ya mencionada que lo intermedia con la mayor laguna Frías, en la que a su vez aquélla se vierte. Es un fenómeno hidrológico particular que justifica un registro periódico y su correspondiente evaluación.

20 Registro histórico de antecedentes volcánicos y sísmicos en la Patagonia austral y la Tierra del Fuego (Magallania, vol. 36-2, Punta Arenas, 2008), pág. 12.

\section{CONCLUSIONES}

Sobre la base de lo constatado hasta el presente es posible establecer algunas conclusiones preliminares:

a) Geográficas

Es obvio que el aumento de tamaño del lago Dickson conforma un hecho de interés por lo excepcional, al punto de estar doblando virtualmente en la actualidad la superficie que se le conociera hasta principios del siglo XX. No hay registro alguno sobre otro caso semejante en la Patagonia.

\section{b) Hidrográficas}

Partiendo del hecho constatado, esto es, la extensión de la cobertura lacustre hacia el noreste, podría darse, en la irregularidad del flujo de agua de fusión del hielo, su derrame alternativo hacia el sureste y hacia el noreste, siquiera de manera temporal inclusive con flujo de agua desde la laguna Frías al lago Dickson como se comprobara en la inspección CONAF-DGA de 1998 (durante la que se habría registrado la misma cota de altura sobre el nivel del mar para ambos depósitos). De ocurrir así en forma permanente podría revivir bajo distintas circunstancias la hipótesis de Moyano y Del Castillo en cuanto a la intercomunicación de las cuencas hidrográficas de los sistemas del Lago Argentino-Río Santa Cruz, y Lagos del Paine-Río Serrano ${ }^{21}$. Más que conclusión es una conjetura sugerente cuya validación cabe a los expertos en hidrología.

c) Políticas

La situación descrita, obra exclusiva de la naturaleza, ha devenido un hecho absolutamente inesperado para Chile y Argentina desde que se ha generado un depósito lacustre que de haber sido hasta fines del siglo XX un accidente geográfico exclusivo del primero, es en el presente un espejo compartido con Argentina, vale decir un nuevo lago binacional, tal y como lo son por decisión política los lagos

21 Debe tenerse presente que el único caso conocido de intercomunicación fluvial conocido en la geografía sudamericana es el del canal Casiquiare en Venezuela, que une los sistemas de los ríos Orinoco y Amazonas. 


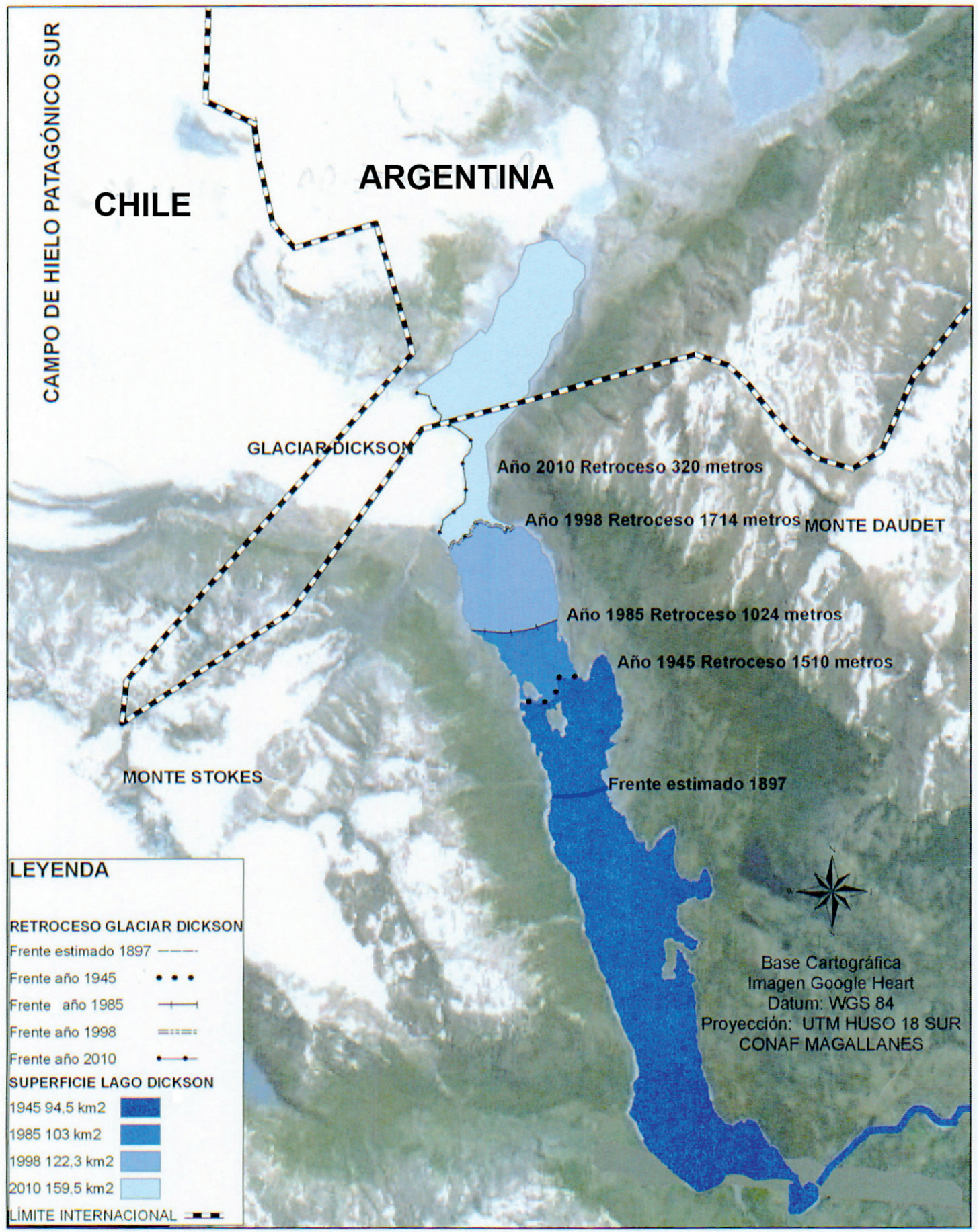

Fig. 3. Plano que muestra el retroceso del glaciar Dickson entre 1897 y 2010, elaborado por CONAF-MAGALLANES en enero del 2010. 
Palena-General Vintter ${ }^{22}$; General Carrera-Buenos Aires; Cochrane-Pueyrredón; O'Higgins-San Martín; Deseado y Fagnano ${ }^{23}$; y Errázuriz-Roca.

Se trata de una situación única, por imprevista, aparecida en un sector de la extensa frontera internacional para el que una sentencia arbitral (Laudo de 1902) reconoció la divisoria continental de aguas como elemento natural determinante, $\mathrm{y}$ que, sin embargo de lo ocurrido, es inalterable por su origen jurídico. Esta misma situación permite recordar lo que fuera otro hecho geográfico ignorado al tiempo del arbitraje 1898-1902 y cuya sobreviniencia -aunque de distinto origen pues se trató de un distrito territorial desconocido por inexplorado-, generó una controversia que tensionó las relaciones entre Chile y Argentina: el caso de la laguna del Desierto. A la vista de la aceptación tácita de un hecho natural como es el de la materia que motiva este artículo, cabe preguntarse si tal no debió haber sido la actitud de las partes ante el conocimiento tardío de la existencia del depósito mencionado y el hecho de su doble ocupación colonizadora desde dos sectores nacionales, por el norte (Chile) y por el sur (Argentina), y, por consecuencia, haber convenido razonablemente en requerir del antiguo árbitro real la precisión del trazado particular hecho en su hora por su representante técnico. Amén de justa y equitativa, habría sido además una decisión pacífica y constructiva. Pero las circunstancias hicieron que el rumbo de la controversia fuera diferente y con el resultado conocido.

\section{AGRADECIMIENTOS}

El autor deja constancia de su especial reconocimiento a la señora Karina Vergara, técnico de la Sección Cartografía y Planificación de CONAFMAGALLANES, por su colaboración en la obtención de imágenes satelitales del área de interés, en las mediciones y cálculos correspondientes, y en la elaboración de la cartografía explicativa. También se agradece la cooperación brindada por el ingeniero Carlos Olave, Sección Climatología, Área de Geografía, Instituto de la Patagonia, Universidad de Magallanes.

22 Se dan los nombres correspondientes en cada país; el primero en Chile y el segundo en Argentina.

23 Denominaciones comunes.

\section{FUENTES DE CONSULTA}

Inéditas

Ministerio de Obras Públicas. Dirección General de Aguas XII Región Magallanes y Antártica Chilena. S/fecha Informe de situación formación laguna en glaciar Dickson. Punta Arenas.

Empresas

Agostini, AlBERTO M. DE. 1945. Andes Patagónicos. Editorial S.E.I. Buenos Aires.

-1960. Magallanes y Canales Fueguinos. Punta Arenas.

ANIYA, M., H. SATO, R. NARUSE, P. SKVARCA and G. CASASSA. 1996. The use of satellite and airborne imagery to inventory outlet glaciers of the Southern Patagonia Icefield, South America. Photogrammetric Engineering and Remote Sensing, 62(12): 1361-1369.

BUSCAINI, GINO y SILVIA METZELTIN. 2000. Patagonia. Tierra mágica para viajeros y alpinistas. Desnivel Ediciones. Barcelona.

CASASSA, GINO Y ANDRES RIVERA. 2001. Campo de Hielo Patagónico Sur: su historia. Anales del Instituto de la Patagonia, Serie Ciencias Humanas, vol. 29:29-78. Punta Arenas.

CASASSA, G. J. L. RODRIGUEZ, A. RIVERA and F. BOWN (in press). A new glacier inventory for the Southern Patagonia Icefield and areal changes 1986-2000. Global Land Ice Monitoring from Space (GLIMS) book. En prensa.

DEL CASTILLO, AGUSTIN. 1979. Exploración de Santa Cruz y Costas del Pacífico. Ediciones Marymar. Buenos Aires.

LISTA. RAMON. 1896. Viaje a los Andes Australes. Anales de la Sociedad Científica Argentina, tomo XLI. Primer Semestre de 1896. Buenos Aires.

LLIBOUTRY, LUIS. 1956. Nieves y glaciares de Chile. Ediciones de la Universidad de Chile. Santiago de Chile.

MARTINIC B., MATEO. 2002. Marinos de a caballo. Exploraciones terrestres de la Armada de Chile en la Patagonia austral y la Tierra del Fuego 1877-1897. Edición, introducción y notas de... Universidad de Magallanes-Universidad de Playa Ancha. Valparaíso. -2006. La exploración de Otto Nordenskjold y su contribución al conocimiento geográfico del interior del distrito fluvio-lacustre de Ultima Esperanza (1896). Actas del V Congreso de Historia Regional de Magallanes. Ediciones de la Universidad de Magallanes. Punta Arenas. 
-2008. Registro histórico de antecedentes volcánicos y sísmicos en la Patagonia austral y la Tierra del Fuego. Magallania, vol. 36-2. Punta Arenas.

MOYANO, CARLOS M. 1931. Viajes de exploración a la Patagonia (1877-1890). Buenos Aires.

RIVERA, A and G. CASASSA. 2004. Ice elevation, areal, and frontal changes of glaciers from National park Torres del Paine, Southern Patagonia Icefield. Artic, Antarctic and Alpine Research, 36(4), 379-389.

RIVERA, ANDRES y GINO CASASSA. 2007. Panel presentado en el Museo Philippi de Valdivia (http://www.glaciología. cl/dickson.htm).

SKOTTSBERG, CARL.2004. La Patagonia salvaje. Zagier \& Urruty Publications. Buenos Aires.

Cartografía

Campo de Hielo Patagónico Sur. Mosaico de imágenes TM del Campo de Hielo Patagónico Sur, 14 de enero de 1986.

Demarcación de límites entre Chile i la República Argentina. Plano IX. Entre $49^{\circ}$ i $52^{\circ}$ Lat. Comisiones Chilena y Argentina de Límites. Escala 1:500.000. 1906.

Sketch map of south Western Patagonia. Otto Nordenskjold. 1897.
Map of the Magellan Territories. Otto Nordenskjold. Escala 1:500.000. 1897.

Mapa de Chile. Cuarterón $49^{\circ}-51^{\circ} \mathrm{S} / 71^{\circ}-76^{\circ}$ O. Oficina de Mensura de Tierras. Escala: 1:500.000. Santiago 1910.

Plano Preliminar (1627 "D”) Lago Argentino. Compilado de fotografías trimetrogónicas realizadas por la American Air Force desde enero a marzo de 1945 y de otras fuentes proporcionadas al Servicio de Cartas Aéreas por U.S. Geological Survey. Junio 1947.

República de Chile. Plano Chaltel o Fitz Roy 4900-7200. Escala 1:250.000. Instituto Geográfico Militar. Santiago 1954.

República de Chile. Plano Chaltel o Fitz Roy 4200-7200. Escala 1:500.000. Instituto Geográfico Militar. Santiago 1972.

Fotografía aérea

Tomas 91 PC 5M 4028411 R 19, 20 y 21. American Air Force. 1945.

Imagenografía digital

Google maps 2010. 